\title{
HEALTH - RELATED QUALITY OF LIFE AND SOME ASSOCIATED FACTORS AMONG THE ELDERLY LIVING IN THREE COMMUNES OF HA NAM PROVINCE, 2019
}

\author{
Tran Quynh Anh $\bowtie$, Pham Thi Thu Trang , Do Vu Minh Ha \\ School of Preventive Medicine and Public Health
}

Caring for an aging population is an emerging public health problem, and the quality of life (QoL) among the elderly is a significant concern. Our study aimed to describe the health - related quality of life (HRQoL) and factors associated with good HRQoL among the elderly in three communes of Hanam province in Vietnam. A cross - sectional design was used with a sample size of 479 participants aged 60 and above. HRQoL was measured using the SF - 36. Comparison of characteristics between those with high HRQoL and those with low HRQoL was done using Pearson chi - square tests. Results were reported using descriptive statistics and odds ratios with $95 \% \mathrm{Cl}$ (Confidence Interval). Many of the elderly had moderate HRQoL (41.3\%), and elderly men were more likely to have higher QoL in terms of physical health and psychological health than elderly women. Our findings also indicated that some factors including older age, low educational level, those not living with their spouse, poor financial condition, having more than two health problems and possessing unhealthy drinking behaviors were significantly positive associated with HRQoL. Findings suggest interventions are needed to improve the quality of life among the elderly in rural areas of Vietnam. Keywords: Health - related Quality of Life, HRQoL, elderly, associated factors.

\section{INTRODUCTION}

Improving the Health - related Quality of Life (HRQoL) among the elderly is a significant problem in caring for the aging population in may countries in the world. HRQoL is a multi - dimensional concept that includes domains related to physical, mental, emotional, and social functioning. It goes beyond direct measures of population health, life expectancy, and causes of death, and focuses on the impact health status has on quality of life.

Worldwide, there have been many studies conducted on HRQoL of the elderly showing low and average HRQoL overall mean scores, ranging from 40 to 50 , in Taiwan ${ }^{2}$, Italy ${ }^{3}$ with

Corresponding author: Tran Quynh Anh,

School of Preventive Medicine and Public Health

Email: tranquynhanh@hmu.edu.vn

Received: 05/04/2021

Accepted: 20/05/2021 selection of elderly subjects from four programs to achieve heterogeneity in the "health status", "functional capacity", "gender", and "age" variables. The Clinical Impact Method was used, consisting of the spontaneous and elicited selection by the respondents of relevant items to the construct Quality of Life in Old Age from a previously elaborated item pool. The respondents rated each item's importance using a 5 - point Likert scale. The product of the proportion of elderly selecting the item as relevant (frequency, and Spain. ${ }^{4}$ As Vietnam confronts the challenge stemming from a growing aging population, the importance of HRQoL for the elderly becomes apparent, and recently, more attention has been paid to the topic. According to results from Vietnam Population Change and Family Planning Survey in 2016, the aging index had increased from $18.2 \%$ in 1989 to $50.1 \%$ in 2016 . These showed 
that the population aging in Vietnam had been growing very fast over three decades ${ }^{11}$.

Some of studies in Vietnam that can be mentioned are a study of Luong et al. in Hai Duong province ${ }^{5}$, study of Thang N. et al. in Thai Binh province. ${ }^{6}$ A study in 2017 reported that HRQoL score among the people in Thuy Van commune of Thua Thien - Hue province was moderate at 56.8. HRQoL positively associated with age, education status, economic status, marital status, health problems. ${ }^{7}$

In recent years, although the physical and spiritual life of the elderly has improved, there are still many challenges in terms of HRQoL among older Vietnamese people. One reason is a lack of evidence to design and implement relevant policies and intervention programs to improve HRQoL for seniors. ${ }^{8}$ There were very few studies conducted on HRQoL among the elderly, especially among those who are living in rural areas in general and northen rural areas in particular.

Therefore, this study was conducted to describe the HRQoL among the elderly living in three communes in Hanam province in 2019 and identify the factors associated with high/low HRQoL?.

\section{METHOD}

\section{Subjects}

This study used a cross - sectional study design and the eligible participants were people aged 60 or older living in Dong Du commune of Binh Luc district, Thuy Loi commune of Kim Bang district or Chau Giang commune of Duy Tien district. The participants were recruited by using convenience sampling method. We chose all people who aged 60 years and above had been living in three communes for more than three years.

The sample size was calculated using the following formula with the assumption that $10 \%$ of the recruited would decline to partipate in the study.

In the formula above, $p$ is the prevalence of the participants who had good HRQoL according to the study conducted on the elderly living in three communes of Thai Binh province using the Short Form (36) Health Survey (SF - 36) questionnaire in 2017 , which is equal to $0.179^{6} ; Z=1.96$; and $=0.15$.

The minimum sample size was estimated to be 440 participants, and a total of 479 people were enrolled in the study.

\section{Method}

\section{Instrument and data collection}

The health of the participants was measured using SF - 36, which consisted of 36 items divided into eight sections. The eight sections measured vitality, physical functioning, bodily pain, general health perceptions, physical role functioning, emotional - role functioning, social role functioning, and mental health. Each participant answered the questions in the eight sections and received eight scaled scores, which were the weighted sums of the questions in each section. Information collected about the socio - demographic characteristics of the participants included age, gender, religion, education, marital status, occupation, financial status and health problems. Current use of alcohol was assessed using the Alcohol Use Disorders Identification Test-C (AUDIT - C) which was a 3 - item alcohol screening tool that helped identify persons who were hazardous drinkers or had active alcohol use disorders (including alcohol abuse or dependence).

\section{Statistical analysis}

Data were cleaned and checked for extreme and illogical data before entered into a Epidata database version 3.1. Data were converted into .dta file and analyzed using Stata software 
version 14.1. The whole eight sections of SF - 36 were scored on a scale of 0 to 100 with higher scores indicating better HRQoL. A section was treated as missing when more than $20 \%$ of its items were left blank. Descriptive statistics and odds ratios with $95 \% \mathrm{CI}$ (Confidence Interval) were used to report results.

\section{Ethical considerations}

All participants were informed that their participation was completely voluntary and were assured that their responses would remain anonymously. All personal identifications of the participants were protected. The survey was performed with agreement and authorization from the Directors of Hanam Department of Health.

\section{RESULTS}

Among 479 participants, $55.3 \%$ were women and $44.7 \%$ were men; $45.7 \%$ were aged $60-69$ years, $34.7 \%$ were aged $70-79$ years, and $19.7 \%$ were over 80 years old. The majority $(61.4 \%)$ were farmers/workers, married $(75.4 \%)$ and had moderate income or less $(91.0 \%)$. Most $(88 \%)$ of the participants had high school education or lower, and the prevalence of illiteracy was $7.5 \%$. All sociodemographic characteristics were presented in Table 1.

Table 1. General information about participants

\begin{tabular}{|c|c|c|c|}
\hline \multirow{2}{*}{ Characteristics } & \multirow{2}{*}{ Classifications } & \multicolumn{2}{|c|}{ Total } \\
\hline & & $\mathbf{n}$ & $\%$ \\
\hline \multirow[t]{2}{*}{ Gender } & Male & 214 & 44.7 \\
\hline & Female & 265 & 55.3 \\
\hline \multirow[t]{3}{*}{ Age group } & $60-69$ & 219 & 45.7 \\
\hline & $70-79$ & 166 & 34.7 \\
\hline & $\geq 80$ & 94 & 19.6 \\
\hline \multirow[t]{4}{*}{ Religions } & No religion & 280 & 58.5 \\
\hline & Buddhism & 140 & 29.2 \\
\hline & Christian & 49 & 10.2 \\
\hline & Others & 10 & 2.1 \\
\hline \multirow[t]{2}{*}{ Marital status } & Not living with spouses & 118 & 24.6 \\
\hline & Living with spouses & 361 & 75.4 \\
\hline \multirow[t]{4}{*}{ Education level } & No education & 36 & 7.5 \\
\hline & $\begin{array}{l}\text { Secondary school level } \\
\text { or less }\end{array}$ & 378 & 78.9 \\
\hline & Senior high school & 44 & 9.2 \\
\hline & University and posture & 21 & 4.4 \\
\hline
\end{tabular}




\begin{tabular}{|c|c|c|c|c|}
\hline \multirow{2}{*}{ Characteristics } & & \multirow{2}{*}{ Classifications } & \multicolumn{2}{|c|}{ Total } \\
\hline & & & $\mathbf{n}$ & $\%$ \\
\hline \multirow{5}{*}{\multicolumn{2}{|c|}{ Occupation }} & Unemployees & 25 & 5.2 \\
\hline & & Freelancers & 57 & 11.9 \\
\hline & & Government officers & 82 & 17.1 \\
\hline & & Workers/Farmers & 294 & 61.4 \\
\hline & & Others & 21 & 4.4 \\
\hline \multirow{3}{*}{\multicolumn{2}{|c|}{ Financial status }} & Poor & 322 & 67.2 \\
\hline & & Middle & 149 & 31.1 \\
\hline & & Rich & 8 & 1.7 \\
\hline \multirow{4}{*}{ Health risk behaviors } & \multirow[t]{2}{*}{ Alcohol use } & Using & 104 & 22.1 \\
\hline & & Not using & 375 & 77.9 \\
\hline & \multirow[t]{2}{*}{ Tobacco use } & Using & 103 & 21.5 \\
\hline & & Not using & 376 & 78.5 \\
\hline
\end{tabular}

Table 2 presented the proportions of participants with very low to high physical health, mental health and HRQoL, stratified by gender.

Table 2. Health - related quality of life among participants

\begin{tabular}{lllccccc}
\hline & \multicolumn{2}{c}{ Male } & \multicolumn{2}{c}{ Female } & Total & $\%$ \\
\hline \multirow{3}{*}{ Physical health } & Very low & 24 & 11.2 & 45 & 17 & 69 & 14.3 \\
\cline { 2 - 8 } & Low & 50 & 23.4 & 92 & 34.7 & 142 & 29.7 \\
\cline { 2 - 8 } & Moderate & 82 & 38.3 & 83 & 31.3 & 165 & 34.5 \\
\cline { 2 - 8 } Mental Health & High & 58 & 27.1 & 45 & 17.0 & 103 & 21.5 \\
\hline & Very low & 1 & 0.5 & 7 & 2.6 & 8 & 1.7 \\
\cline { 2 - 8 } & Low & 36 & 16.8 & 55 & 20.8 & 91 & 19.0 \\
\cline { 2 - 8 } & Moderate & 69 & 32.2 & 93 & 35.1 & 162 & 33.8 \\
\cline { 2 - 8 } HRQoL & High & 108 & 50.5 & 110 & 41.5 & 218 & 45.5 \\
\hline & Very low & 5 & 2.3 & 15 & 5.7 & 20 & 4.2 \\
\cline { 2 - 8 } & Low & 50 & 23.4 & 79 & 29.8 & 129 & 26.9 \\
\cline { 2 - 8 } & Moderate & 85 & 39.7 & 113 & 42.6 & 198 & 41.3 \\
\cline { 2 - 7 } & High & 74 & 34.6 & 58 & 21.9 & 132 & 27.6 \\
\hline
\end{tabular}

Regarding physical health, those with moderate and high level accounted for $34.5 \%$ and $21.5 \%$ of the participants, respectively, while $14.3 \%$ and $29.7 \%$ had very low and low level of physical health, respectively. The proportion of males who had moderate physical health score were the highest at $38.3 \%$. Meanwhile, about a third $(34.7 \%)$ of the women had low physical health score. 
Regarding mental health, $45.5 \%$ had high score, $33.8 \%$ had moderate score, and only $1.67 \%$ had very low score. There was no significant difference between men and women in terms of mental health level $(p>0.05)$.

Regarding HRQoL classification, 27.6\% had high HRQoL, $41.3 \%$ had moderate HRQoL, and $26.9 \%$ had low HRQoL. Few (4.2\%) had very low HRQoL. The proportion of males with high HRQoL was higher than females ( $34.6 \%$ vs $21.9 \%$, respectively). By way of contrast, the proportion of females with low HRQoL was higher than males ( $29.8 \%$ vs $23.4 \%$, respectively), similar to very low HRQoL (5.7\% vs $2.3 \%$, respectively)

Table 3. Factors associated with HRQoL among participants

\begin{tabular}{|c|c|c|c|c|c|c|}
\hline & \multirow[t]{2}{*}{ Characteristics } & \multicolumn{2}{|c|}{$\begin{array}{c}\text { Good } \\
\text { HRQoL }\end{array}$} & \multicolumn{2}{|c|}{$\begin{array}{l}\text { Not good } \\
\text { HRQoL }\end{array}$} & \multirow[t]{2}{*}{ OR (95\%Cl) } \\
\hline & & $\mathbf{n}$ & $\%$ & $\mathbf{n}$ & $\%$ & \\
\hline \multirow{3}{*}{ Age group } & $60-69$ & 171 & 78.1 & 48 & 21.9 & \\
\hline & $70-79$ & 110 & 66.3 & 56 & 33.7 & $1.8(1.07-3.04)$ \\
\hline & $\geq 80$ & 49 & 52.1 & 45 & 47.9 & $3.3(1.92-5.59)$ \\
\hline \multirow{2}{*}{ Gender } & Male & 159 & 74.3 & 55 & 25.7 & \\
\hline & Female & 171 & 64.5 & 94 & 36.5 & $1.6(1.07-2.37)$ \\
\hline \multirow{2}{*}{$\begin{array}{l}\text { Educational } \\
\text { level }\end{array}$} & Junior high school and above & 52 & 80 & 13 & 20 & \\
\hline & Senior high school or less & 278 & 67.2 & 136 & 32.8 & $1.95(1.02-3.7)$ \\
\hline \multirow{2}{*}{ Marital status } & Living with spouses & 261 & 72.3 & 100 & 27.7 & \\
\hline & Not living with spouses & 69 & 58.5 & 49 & 41.5 & $1.85(1.2-2.9)$ \\
\hline \multirow{2}{*}{ Religion } & No religion & 194 & 69.3 & 86 & 30.7 & \\
\hline & Having religion & 136 & 68.3 & 63 & 31.7 & $1.05(0.7-1.5)$ \\
\hline \multirow[b]{2}{*}{ Occupation } & Having occupation & 315 & 69.4 & 139 & 30.6 & \\
\hline & No occupation & 15 & 60 & 10 & 40 & $\begin{array}{c}1.51(0.66- \\
3.45)\end{array}$ \\
\hline \multirow{2}{*}{$\begin{array}{l}\text { Financial } \\
\text { status }\end{array}$} & Not poor & 125 & 79.6 & 32 & 20.4 & \\
\hline & Poor & 205 & 63.7 & 117 & 36.3 & $3.0(1.37-5.56)$ \\
\hline \multirow[b]{2}{*}{ Health status } & $<2$ health problems & 224 & 73.7 & 80 & 26.3 & \\
\hline & $\geq 2$ health problems & 106 & 60.6 & 69 & 39.4 & $\begin{array}{c}1.82(1.22- \\
2.72)\end{array}$ \\
\hline \multirow{2}{*}{$\begin{array}{l}\text { Unhealthy } \\
\text { alcohol use }\end{array}$} & No & 268 & 66.7 & 134 & 33.3 & \\
\hline & Yes & 62 & 80.5 & 15 & 19.5 & $2.2(1.13-3.77)$ \\
\hline
\end{tabular}

Table 3 presented factors associated to HRQoL. Higher age groups were significantly associated with increased odds of having worse HRQoL; participants in the age group 70 - 79 years old and age group 80 years old or older were $1.8(95 \% \mathrm{Cl}: 1.07-3.04)$ and $3.3(95 \% \mathrm{Cl}: 1.92-5.59)$ times more 
likely to have poor HRQoL than those in the age group 60 - 69 years old. Women were 1.6 (95\% $\mathrm{Cl}: 1.07-2.37)$ times more likely to have poor HRQoL compared to men. Participants who had senior high school education or lower were 1.95 (95\% Cl: 1.02 - 3.7) times more likely to have poor HRQoL than those with junior high school education. Other factors significantly associated with HRQoL were having poor financial status, not living with spouse, having more than 2 health problems, and having unhealthy drinking behaviors.

\section{DISCUSSION}

Our results revealed that most of the participants had moderate HRQoL. This was consistent with results from a 2018 study conducted in Tien Hai district of Thai Binh province and Thanh Binh district of Dong Thap province. In that study, the mean score of HRQoL was on moderate level. ${ }^{6}$

Our findings showed that having poor financial status, not living with spouse, having more than 2 health problems, and having unhealthy drinking behaviors were significantly associated with HRQoL. These results were consistent with previous research. Several investigations have shown that socio demographic variables, health problems and health behaviors such as tobacco use can affect SF - 36 scores. Recent studies have indicated that HRQoL domain scores among the elderly are influenced by socio - demographic variables such as age ${ }^{11,12}$, gender ${ }^{13,14}$, marital status ${ }^{15}$, ${ }^{16}$, education level ${ }^{17}$ and economic condition. ${ }^{18}$ A study conducted among 316 elderly people randomly selected in Tan An commune, Hai Duong province, Vietnam, showed that age groups, health status, family status and income sources ${ }^{19}$ were related to quality of life.

By analyzing HRQoL stratified by gender, this study showed that women were worse than men in all SF - 36 scales. In a sample of 1688 individuals aged 18 years or older, Li et al. found lower scores among women in the following dimensions: Physical functioning, Bodily pain, General health and Vitality. ${ }^{20}$ Another study by Wyss et al. in Tanzania reported similar results, with women obtained lower scores than men in all SF - 36 scales. $^{21}$ Our finding was also consistent with those from the study conducted by Nilsson on QoL of seniors in a rural area of Bangladesh $^{9}$ and another study implemented in FilaBavi, Vietnam. ${ }^{10}$ This suggests it is important to understand factors affecting the QoL in each gender in order to better inform the interventions to reduce gender disparity in HRQoL at old age.

As shown in Table 3, higher age groups were significantly associated with lower HRQoL. These results were similar to the findings by Damayanthi et al. in 2018 ${ }^{14}$; Campos et al. in 201422; and Raggi et al. in 20164. Unsurprisingly, elderly living in better economic condition had a higher HRQoL than others. This result supports previous studies in that elderly with higher income had a better QoL. ${ }^{23}$ According to Fleck et al., levels of income and education, good living conditions and health, a good network of friends, the maintenance of good family relationships were factors that could contribute to higher quality of life, subjective welfare, a sense of self - efficacy, and thus for a better overall functioning of the elderly ${ }^{24}$. We were able to confirm that elderly individuals living with spouses reported a better HRQoL than those with no spouses. These findings were similar with results of Lima et al. ${ }^{25}$; Nam et al. ${ }^{7}$; Hoi et al. ${ }^{8}$

Our finding that those with two or more health problems had higher odds of having poor HRQoL was in line with another study in Zimbabwe which reported chronic health 
conditions significantly affected HRQoL among grandparents ${ }^{26}$. Wang $R$. et al in a study conducted on the elderly living in Shanghai city suggested that the primary influencing risk factors of HRQL included chronic diseases, age, frequency of activities, and geographical region. ${ }^{28}$ Campbell et al., which indicated that there was a significant relationship between tobacco use and HRQoL among clients in substance use disorders treatment. ${ }^{27}$

Our study paves the ways for further examination of HRQoLin the elderly and provides evidence for planning policies and programs that enhance quality of life and decrease burden of diseases for the elderly. However, due to the cross - sectional nature, which cannot ascertain the temporal relationship between HRQoL and the significant factors found in this study, it is difficult to make any causal inference that low HRQoL was directly caused by these factors. Studies with prospective longitudinal design should be conducted to address this issue.

\section{CONCLUSION}

Most of elderly people had moderate HRQoL, in which male elderly was more likely to have higher level of QoL in physical health and psychological health compared to female elderly. Older age, low educational level, not living with spouses, poor economic condition, having more than two health problems and having unhealthy drinking behaviors were significantly associated with increased odds of lower level of HRQoL.

\section{REFERENCES}

1. GSO. Population and Housing Census 2019.; 2019.

2. Ho T - J, Christiani DC, Ma T - C, et al. Effect of Qigong on quality of life: a cross sectional population - based comparison study in Taiwan. BMC Public Health. 2011;11(1):546. doi:10.1186/1471 - 2458 - 11 - 546

3. Paschoal SMP, Filho WJ, Litvoc J. Development of Elderly Quality of Life Index

4. - Eqoli: Item Reduction and Distribution into Dimensions. Clinics. 2008;63(2):179 - 188.

5. Raggi $A$, Corso $B$, Minicuci $N$, et al. Determinants of Quality of Life in Ageing Populations: Results from a Cross - Sectional Study in Finland, Poland and Spain. PLoS One. 2016;11(7). doi:10.1371/journal.pone.0159293

6. Duong Huy Luong. Nghiên cứu chất lượng cuộc sống người cao tuổi và thử nghiệm giải pháp can thiệp ở huyện Chí Linh, tỉnh Hải Dương. Luận án tiến sĩ y học-Học viện Quân Y 2010

7. Thắng $\mathrm{NT}$, Vũ $\mathrm{T}, \mathrm{Kỷ} H \mathrm{HT}$, Hương $\mathrm{LTT}$, Anh LV. Quality of life of elderly people in Tien Hai district, Thai Binh Province and Thanh Binh district, Dong Thap Province in 2018. Vietnam Journal of Public Health. No. 472019 p.39-46

8. Nhi NTH, Khanh DVD. Quality of life and associated factors among the elderly in Huong So ward, Hue City, Thua Thien-Hue Province. Vietnam Journal of Preventive Medicine. 2019. 29 (11): 254

9. Hoi L, Chuc N, Lindholm L. Health - related quality of life, and its determinants, among older people in rural Vietnam. BMC public health. 2010;10:549. doi:10.1186/1471 2458 - 10 - 549

10. Nilsson J, Grafström M, Zaman S, Kabir ZN. Role and function: Aspects of quality of life of older people in rural Bangladesh. Journal of Aging Studies. 2005;19(3):363 374. doi:10.1016/j.jaging.2004.07.006

11. Hoi LV, Chuc NT, Lindholm L. Health related quality of life, and its determinants, among older people in rural Vietnam. BMC Public Health. 2010;10:549. doi:10.1186/1471 2458 - 10 - 549

12. HuongNT,HaLTH,TienTQ.Determinants 
of Health - Related Quality of LifeAmong Elderly: Evidence From Chi Linh Town, Vietnam. Asia Pac J Public Health. 2017;29(5_suppl):84S 93S. doi:10.1177/1010539517704041

13. Tajvar $M$, Arab M, Montazeri A. Determinants of health - related quality of life in elderly in Tehran, Iran. BMC Public Health. 2008;8(1):323. doi:10.1186/1471 - 2458 - 8 323

14. Ćwirlej - Sozańska A, Sozański B, Wiśniowska - Szurlej A, Wilmowska Pietruszyńska A. Quality of life and related factors among older people living in rural areas in south - eastern Poland. Ann Agric Environ Med. 2018;25(3):539 - 545. doi:10.26444/ aaem/93847

15. Damayanthi HDWT, Moy FM, Abdullah $\mathrm{KL}$, Dharmaratne SD. Health related quality of life and its associated factors among community

16. dwelling older people in Sri Lanka: A cross - sectional study. Archives of Gerontology and Geriatrics. 2018;76:215 - 220. doi:10.1016/j. archger.2018.03.009

17. Martinez - Martin P, Prieto - Flores M - E, Forjaz MJ, et al. Components and determinants of quality of life in community - dwelling older adults. Eur J Ageing. 2012;9(3):255 - 263. doi:10.1007/s10433 - 012 - 0232 - x

18. Del Core MA, Ahn J, Wukich DK, et al. Gender Differences on SF - 36 Patient Reported Outcomes of Diabetic Foot Disease. Int J Low Extrem Wounds. 2018;17(2):87 - 93. doi:10.1177/1534734618774664

19. Knesebeck OVD, Wahrendorf M, Hyde M, Siegrist J. Socio - economic position and quality of life among older people in 10 European countries: results of the SHARE study. Ageing \& Society. 2007;27(2):269 - 284. doi:10.1017/ s0144686X06005484

20. Paskulin L, Vianna L, Molzahn AE. Factors associated with quality of life of Brazilian older adults. International Nursing Review. 2009;56(1):109 - 115. doi:10.1111/j.1466 7657.2008.00671.x

21. Tra LTM, Quang NV, Duc TQ. Quality of life and some associated factors among the elderly in An Nhon town, Binh Dinh Province in 2017. Journal of Health and Development Studies. 2(3)-2018 p.31-38

22. Li L, Wang HM, Shen Y. Chinese SF - 36 Health Survey: translation, cultural adaptation, validation, and normalisation. I Epidemiol Community Health. 2003;57(4):259 - 263. doi:10.1136/jech.57.4.259

23. Wyss K, Wagner AK, Whiting $D$, et al. Validation of the Kiswahili version of the SF - 36 Health Survey in a representative sample of an urban population in Tanzania. Qual Life Res. 1999;8(1 - 2):111 - 120. doi:10.1023/a:1026431727374

24. Campos ACV, e Ferreira EF, Vargas AMD, Albala C. Aging, Gender and Quality of Life (AGEQOL) study: factors associated with good quality of life in older Brazilian community - dwelling adults. Health and Quality of Life Outcomes. 2014;12(1):166. doi:10.1186/ s12955 - 014 - 0166 - 4

25. Colet $\mathrm{C}$ de F, Mayorga P, Amador TA. Educational level, socio - economic status and relationship with quality of life in elderly residents of the city of Porto Alegre/RS, Brazil. Brazilian Journal of Pharmaceutical Sciences. 2010;46(4):805 - 810. doi:10.1590/S1984 82502010000400023

26. Souza JCRP de, Barros NH de S. A avaliação de qualidade de vida: guia para profissionais da saúde. Rev psiquiatr Rio Gd Sul. 2008;30(1):89 - 90. doi:10.1590/S0101 81082008000100019

27. Lima MG, Barros $M B$ de $A$, César CLG, Goldbaum M, Carandina L, Ciconelli RM. Health related quality of life among the elderly: 
a population - based study using SF - 36 survey. Cad Saúde Pública. 2009;25(10):2159 - 2167. doi:10.1590/S0102 - 311X2009001000007

28. Mhaka - Mutepfa M. Sociodemographic Factors and Health - Related Characteristics That Influence the Quality of Life of Grandparent Caregivers in Zimbabwe: Gerontology and Geriatric Medicine. Published online February 13, 2018. doi:10.1177/2333721418756995

29. Campbell B, Yip D, Le T, Gubner N, Guydish J. Relationship between Tobacco
Use and Health - Related Quality of Life (HRQoL) among Clients in Substance Use Disorders Treatment. J Psychoactive Drugs. 2019;51(1):48 - 57. doi:10.1080/02791072.201 8.1555651

30. Wang R, Wu C, Zhao Y, et al. Health related quality of life measured by SF 36: a population - based study in Shanghai, China. BMC Public Health. 2008;8:292. doi:10.1186/1471 - 2458 - 8 - 292 